\title{
Passion in Sport: On the Quality of the Coach-Athlete Relationship
}

\author{
Marc-André K. Lafrenière, ${ }^{1}$ Sophia Jowett, ${ }^{2}$ \\ Robert J. Vallerand, ${ }^{1}$ Eric G. Donahue, ${ }^{1}$ and Ross Lorimer ${ }^{2}$
} 1 Université du Québec à Montréal and ${ }^{2}$ Loughborough University

\begin{abstract}
Vallerand et al. (2003) developed a dualistic model of passion, wherein two types of passion are proposed: harmonious (HP) and obsessive (OP) passion that predict adaptive and less adaptive interpersonal outcomes, respectively. In the present research, we were interested in understanding the role of passion in the quality of coach-athlete relationships. Results of Study 1, conducted with athletes $(N=157)$, revealed that HP positively predicts a high-quality coach-athlete relationship, whereas OP was largely unrelated to such relationships. Study 2 was conducted with coaches $(N=106)$ and showed that only HP positively predicted the quality of the coach-athlete relationship. Furthermore, these effects were fully mediated by positive emotions. Finally, the quality of the coach-athlete relationship positively predicted coaches' subjective well-being. Future research directions are discussed in light of the dualistic model of passion.
\end{abstract}

Keywords: passion, coach-athlete relationship, positive emotions

Lately, sport psychologists have expressed a growing interest in the coachathlete dyad (Jowett \& Poczwardowski, 2007; Mageau \& Vallerand, 2003). Mutual trust, respect, and support are deemed among the main aspects that contribute to satisfying and successful coach-athlete relationships (Jowett, 2007; Jowett \& Cockerill, 2003; Poczwardowski, Barott, \& Peregoy, 2002). Still, one is left wondering about the psychological factors that allow both athletes and coaches to experience high-quality coach-athlete relationships. We posit that passion (Vallerand et al., 2003) corresponds to such a psychological factor. Indeed, if both the coach and the athlete are passionate toward their sport, this could lead them to develop a positive coach-athlete relationship at the very least because they share a love for their activity and may both fully devote themselves to reach high levels of performance. Thus, the purpose of this article was to investigate the role of passion in the quality of coach-athlete relationships.

Lafrenière, Vallerand, and Donahue are with the Département de Psychologie, Laboratoire de Recherche sur le Comportement Social, Université du Québec à Montréal, Montreal, QC, Canada; Jowett and Lorimer are with the School of Sport \& Exercise Sciences, Loughborough University, Loughborough, U.K. 


\section{The Dualistic Model of Passion}

\section{The Concept of Passion}

In line with self-determination theory (Deci, \& Ryan, 2000), the dualistic model of passion (Vallerand et al., 2003; Vallerand \& Houlfort, 2003; Vallerand \& Miquelon, 2007) proposes that people engage in activities to fulfill their basic psychological needs of autonomy (a sense of personal volition), competence (interacting effectively with the environment), and relatedness (a positive reciprocal connection with others). However, not all activities are evenly successful in satisfying these basic psychological needs and therefore individuals are inclined to develop a preference for certain activities. Of these activities, only a handful will be perceived as particularly important and enjoyable, and will develop into a self-defining activity; these activities become passionate activities.

In line with the above, Vallerand et al. (2003) conceptualize passion as a strong inclination toward a self-defining activity that one likes and finds important, and in which one invests a significant amount of time and energy. Moreover, the dualistic model of passion (Vallerand et al., 2003) posits two distinct types of passion, harmonious and obsessive passion, which can be differentiated in terms of how the passionate activity has been internalized into one's identity. Identity refers to an individual's relevant characteristics and experiences, as well as the social and self-regulation functions that such features serve (see Schlenker, 1985). Harmonious passion refers to a strong desire to engage in the activity freely and results from an autonomous internalization of the activity into the person's identity. This process occurs when individuals have willingly accepted the activity as important. With harmonious passion, the activity occupies an important but not overwhelming space in one's identity. Consequently, harmonious passion for an activity should not instigate conflict with one's other life domains and should allow the person to engage in the passionate activity with an openness that is favorable to positive experiences (Hodgins \& Knee, 2002).

Conversely, obsessive passion results from a controlled internalization of the activity into one's identity. This process originates from intrapersonal and/or interpersonal pressure either because particular contingencies are attached to the activity, such as self-esteem, or because the excitement derived from activity engagement becomes uncontrollable. While the controlled internalization leads the activity to be part of the person's identity, the values and regulations related to the activity are then only partially internalized in identity (see Vallerand, 2008). In other words, obsessive passion does represent an important part of one's identity; however individuals with obsessive passion are not completely in control of the activity since it is not properly integrated. Therefore, individuals with an obsessive passion experience an uncontrollable urge to engage in their activity. As a result, they run the risk of experiencing conflict with other life domains and negative consequences during and after engagement in the passionate activity.

Research has provided empirical support for the passion conceptualization. Results from exploratory and confirmatory factor analyses supported the twofactor structure of the Passion Scale (Rousseau, Vallerand, Ratelle, Mageau, \& Provencher, 2002; Vallerand et al., 2003, Study 1; Vallerand et al., 2006, Study 1). 
Moreover, results using the Passion Scale demonstrated that both types of passion were positively correlated with the activity being perceived as part of their identity as measured by the Inclusion in the Other Self Scale (Aron et al., 1992). Furthermore, harmonious passion and obsessive passion have been found to be positively correlated with measures of activity valuation and measures of the activity being perceived as a passion. However, the two types of passion have been found to lead to different predictions with respect to various outcomes (Vallerand et al., 2003, Study 1). Thus, harmonious passion was positively correlated with general positive affect and psychological adjustment indices (Rousseau \& Vallerand, 2003, 2008; Vallerand et al., 2003, Study 2; Vallerand et al., 2006, Study 3; Vallerand et al., 2007, 2008a). Moreover, harmonious passion has been found to be positively associated with positive experiences during activity engagement such as positive emotions and flow (Mageau \& Vallerand, 2007; Mageau, Vallerand, Rousseau, Ratelle, \& Provencher, 2005; Rousseau \& Vallerand, 2003, 2008; Vallerand et al., 2003, Study 1; Vallerand et al., 2006, Study 2). On the other hand, obsessive passion was positively correlated with negative emotions during activity engagement (Vallerand et al., 2003, Study 1; Vallerand et al., 2006, Study 2), rumination when prevented from engaging in the passionate activity (Ratelle et al., 2004; Vallerand et al., 2003, Study 1), and rigid persistence (Rip, Fortin, \& Vallerand, 2006; Vallerand et al., 2003, Studies 3, 4).

\section{Passion and Related Constructs}

The concept of passion has some resemblance with other concepts such as those of intrinsic and extrinsic motivation (Deci \& Ryan, 2000) and flow (Csikszentmihalyi, 1990).

Passion shares some similarity with intrinsic motivation, as both involve interest and liking toward the activity. However, intrinsically motivated activities are typically not seen as being internalized in the person's identity (Deci \& Ryan, 2000). Thus, passion and intrinsic motivation represent different constructs. Furthermore, extrinsic motivation does not entail performing the activity out of enjoyment, but to obtain something outside the activity. Therefore, the fundamental difference between extrinsic motivation and passion is the lack of liking for the activity. Vallerand et al. (2003, Study 2) empirically demonstrated the independence of passion, intrinsic motivation, and extrinsic motivation by showing that harmonious and obsessive passion predicted changes in general positive and negative affect, respectively, over and beyond intrinsic and extrinsic motivation. Overall, it seems that although passion and motivation are both motivational concepts, they represent distinct constructs.

The concept of flow represents a state of intense immersion in an activity (Csikszentmihalyi, 1990). In line with self-determination theory, it is posited that emotions are a consequence of passion. It would be expected that harmonious passion should lead to higher levels of flow because the autonomous internalization of the activity leads the person to engage in the task in a more flexible manner and thus to experience task engagement more fully. Thus, flow is conceptualized as a consequence of passion, and past research (Vallerand et al., 2003; Study 1) has shown that it results mainly from harmonious passion. In sum, while the concept 
of passion does share some conceptual similarities with other constructs, it also differs from them in significant ways both theoretically and empirically.

\section{Passion and Interpersonal Relationships}

The dualistic model of passion (Vallerand et al., 2003) suggests that having an obsessive passion toward an activity should lead to conflict in other life domains, whereas this should not be the case for harmonious passion. Several studies have provided support for this hypothesis. For instance, Vallerand et al. (2003, Study 1) showed that only obsessive passion was positively associated with conflict between the passionate activity and other activities. A subsequent study (Séguin-Lévesque, Laliberté, Pelletier, Vallerand, \& Blanchard, 2003) found that controlling for the amount of time that individuals engaged in the Internet, obsessive passion for the Internet positively predicted conflict with one's romantic partner, whereas harmonious passion was negatively related to conflict. Similarly, a study conducted with English soccer fans (Vallerand et al., 2008b, Study 3) showed that obsessive passion for being a soccer fan predicted conflict between one's passion for soccer and one's romantic relationship that, in turn, predicted lower quality of couple relationships. Conversely, harmonious passion was unrelated to conflict with one's spouse.

The above findings provide support for the dualistic model of passion regarding the role of passion in interpersonal outcomes experienced outside the passionate activity. However, past studies have not addressed whether one's passion can influence relationships in the purview of the passionate activity. It is believed that the two types of passion should influence differently the quality of the relationship in the activity. Specifically, harmonious passion is expected to positively influence the coach-athlete relationship, whereas obsessive passion is hypothesized to be either unrelated or negatively related to the relationship. Further, it is posited that this effect is in large part mediated by positive emotions. Fredrickson (2001; Waugh \& Fredrickson, 2006) demonstrated that the experience of positive emotions in a given context is conducive to high-quality relationships. Presumably because they lead people to open up to others and to engage in positive interpersonal behaviors, such as smiling and connecting with others (Aron, Norman, Aron, McKenna, \& Heyman, 2000), positive emotions should indirectly contribute to the development of high-quality relationships. Given that harmonious passion positively predicts the experience of positive emotions during engagement in the passionate activity (Mageau et al., 2005; Vallerand et al., 2003, Study 1; Vallerand et al., 2006, Studies 2, 3), it can be hypothesized that harmonious passion should indirectly lead to high-quality relationships within the passionate activity through the experience of situational positive emotions. Conversely, because it leads to the experience of fewer positive emotions (Mageau et al., 2005; Vallerand et al., 2003, Study 1; Vallerand et al., 2006) and even at times to negative emotions (Vallerand et al., 2003, Study 1), obsessive passion is expected to be either unrelated or even negatively related to the quality of interpersonal behaviors. Finally, 
it was hypothesized that harmonious passion and obsessive passion would be positively correlated because both entail a love for the activity and a strong identification to it.

\section{The Present Research}

The purpose of the present research was to explore the role of harmonious and obsessive passion in the quality of coach-athlete relationships within two cultures (British and French Canadian). Study 1 focused on the relationship between passion and the quality of the coach-athlete relationship from the athletes' perspective. It was posited that harmonious passion would facilitate the quality of the coach-athlete relationship and that obsessive passion would be either unrelated or negatively related to the quality of relationships. Study 2 sought to replicate Study 1 's findings from the coaches' perspective. Furthermore, Study 2 tested the mediating role of positive emotions in the relation between passion and the quality of coach-athlete relationships. In line with past research (Mageau et al., 2005; Rousseau \& Vallerand, 2003, 2008; Vallerand et al., 2003, Study 1; Vallerand et al., 2006, Studies 2 and 3), it was hypothesized that harmonious passion for coaching should lead to the experience of situational positive emotions, which were expected to be conducive to high-quality coach-athlete relationships. On the other hand, obsessive passion was expected to be either unrelated or even negatively related to situational positive emotions and therefore to be either unrelated or negatively related to high-quality coach-athlete relationships. Finally, the role of quality coach-athlete relationships in coaches' subjective well-being was also assessed. In line with theory and research on the need for relatedness and relationships (Baumeister \& Leary, 1995; McClelland, 1985; Ryan \& Deci, 2007), it was hypothesized that experiencing positive coach-athlete relationships would positively predict subjective well-being in coaches.

\section{Study 1}

Study 1 focused on the role of passion in the coach-athlete relationship from the athletes' perspective. It was hypothesized that harmonious passion would positively predict high-quality relationships with coaches, while obsessive passion would be less predictive of the quality of relationships. More specifically, it was posited that both types of passion would be positively related to commitment to the relationship, since the passionate activity is very important and central to one's identity. However, because harmonious passion is generally associated with the experience of positive emotions, it was posited that harmonious passion would facilitate the coach-athlete relationship the most. Conversely, obsessive passion was expected to be either unrelated or even negatively related to the other dimensions of the coach-athlete relationship. 


\section{Method}

\section{Participants}

The participants were 157 British college athletes (81 males and 76 females) engaged in popular team sports (e.g., hockey, rugby, netball). The average age of the participants was 20.23 years $(S D=1.74$ years). The participants classified their performance level as follows: club level $(N=10 ; 6 \%)$, county level $(N=8$; $5 \%)$, university level $(N=106 ; 68 \%)$, national level $(N=13 ; 8 \%)$, and international level $(N=20 ; 13 \%)$.

\section{Measures}

Passion Toward Sport. Athletes' passion toward sport was assessed using the Passion Scale (Vallerand et al., 2003), an instrument composed of two six-item subscales assessing harmonious and obsessive passion (sample item for harmonious passion: "My sport [e.g., rugby] is in harmony with other activities in my life"; sample item for obsessive passion: "I have difficulties controlling my urge to do my sport [e.g., rugby]"). This scale was completed on a 7-point Likert scale ranging from 1 (not agree at all) to 7 (very strongly agree). The Passion Scale has been used in several studies and has shown high levels of validity and reliability (see Ratelle et al., 2004; Vallerand et al., 2003, Study 1), including with athletes (Vallerand et al., 2003, Studies 2 and 3; Vallerand et al., 2006). In the current study, the subscales were found to have satisfactory internal consistency with Cronbach alphas of .80 and .83 for the harmonious and obsessive passion subscales, respectively.

The Coach-Athlete Relationship. The Coach-Athlete Relationship Questionnaire (CART-Q; Jowett \& Ntoumanis, 2004) was used to assess the athletes' direct perspective and the meta-perspective (Jowett \& Clark-Carter, 2006) of the quality of the relationship with their coach. The direct perspective refers to how athletes perceive the relationship with their coach (e.g., "I like my coach"), whereas the meta-perspective refers to how athletes believe their coach perceives their relationship (e.g., "My coach likes me"). Each perspective is composed of three subscales. Commitment is a four-item subscale that assesses members' intentions to maintain the athletic partnership over time (sample item for the direct perspective: "I am committed to my coach"; sample item for the meta-perspective: "My coach is committed to me"). Closeness is a three-item subscale that assesses the affective tone of the relationship (sample item for the direct perspective: "I respect my coach"; sample item for the meta-perspective: "My coach respects me"). Complementarity is a four-item subscale that assesses cooperative actions (sample item for the direct perspective: "When I am coached by my coach, I am ready to do my best"; sample item for the meta-perspective: "My coach is ready to do his/her best when he/she coaches me"). The Coach-Athlete Questionnaire was completed on a 7-point Likert scale ranging from 1 (not agree at all) to 7 (very strongly agree). In the current study, all subscales demonstrated an acceptable internal consistency ranging from .70 to .82 (see Table 2). 


\section{Procedure}

Athletes were contacted either directly or indirectly via their coaches, through a variety of means (e.g., e-mail, letter) and invited to participate in the study. Prospective participants were informed about the overall aims of the study and the requirements for participation. Participants who consented to participate were supplied with a questionnaire at the beginning of a training session; the questionnaire was then completed and collected immediately.

\section{Results and Discussion}

There was no missing data in the current study. Inspection of the skewness and kurtosis indices for all variables proved normal (values ranged from -.448 to .423 for skewness and from -.619 to .698 for kurtosis). Pearson correlations are presented in Table 1 and means, standard deviations, and reliability coefficients are presented in Table 2. In light of the significant correlation between the two types of passion $(r=.41, p<.05)$ and past research on passion (Vallerand et al., 2003; Vallerand et al., 2006), partial correlations ${ }^{1}$ were conducted (see Table 2). When controlling for obsessive passion, harmonious passion was significantly and positively correlated with all dimensions of the CART-Q. On the other hand, when controlling for harmonious passion, obsessive passion was significantly and positively correlated with only direct commitment and negatively correlated with meta-complementarity.

The present findings provided support for the initial hypotheses. As expected, harmonious passion positively predicted all dimensions of a quality relationship with one's coach. Moreover, obsessive passion was only positively related to direct commitment and negatively related to meta-complementarity. It would thus appear that harmonious passion is associated with higher quality coach-athlete relationships than is obsessive passion.

\section{Study 2}

The purpose of Study 2 was to pursue the investigation of the role of passion in the coach-athlete relationship while making several modifications. First, whereas Study 1 looked at the athlete's perspective, Study 2 explored the coach's perception of the coach-athlete relationship. Second, we sought to uncover the mediating process involved in the relation between passion and the quality of the coachathlete relationship. It was posited that harmonious passion for coaching should lead to the experience of situational positive emotions, which should be conducive to high-quality coach-athlete relationships. Fredrickson (2001) demonstrated that the experience of situational positive affect is conducive to high quality of relationships because it facilitates interpersonal behaviors (e.g., smiling) that are contributing to the development of positive relationships. It was thus posited that positive emotions should mediate the relationship between harmonious passion and the quality of coach-athlete relationships. On the contrary, obsessive passion 


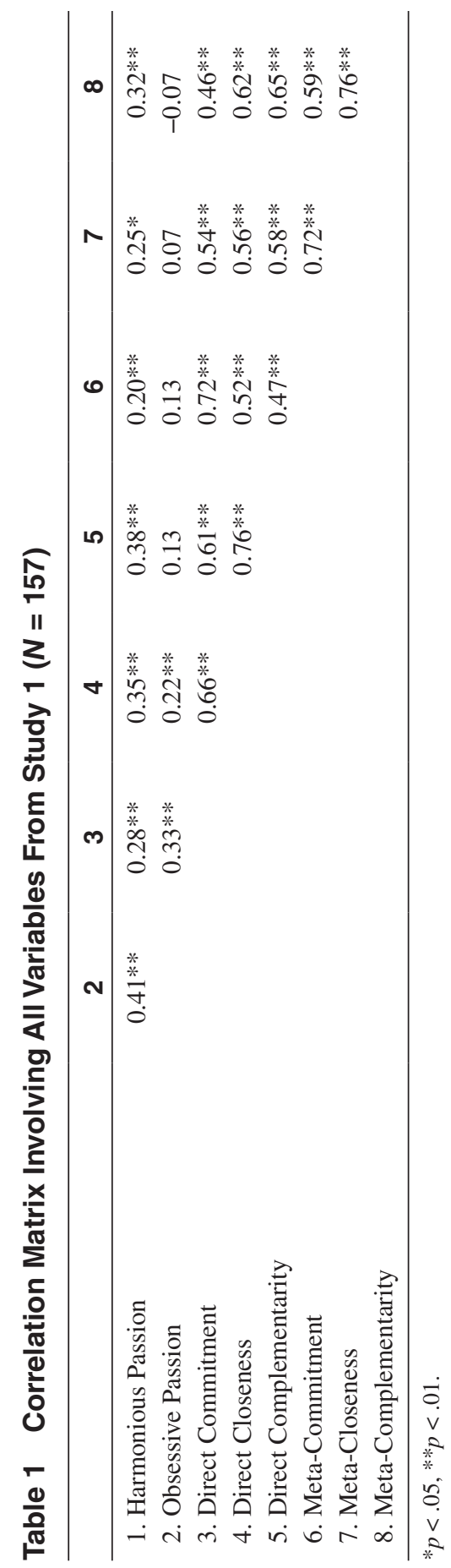




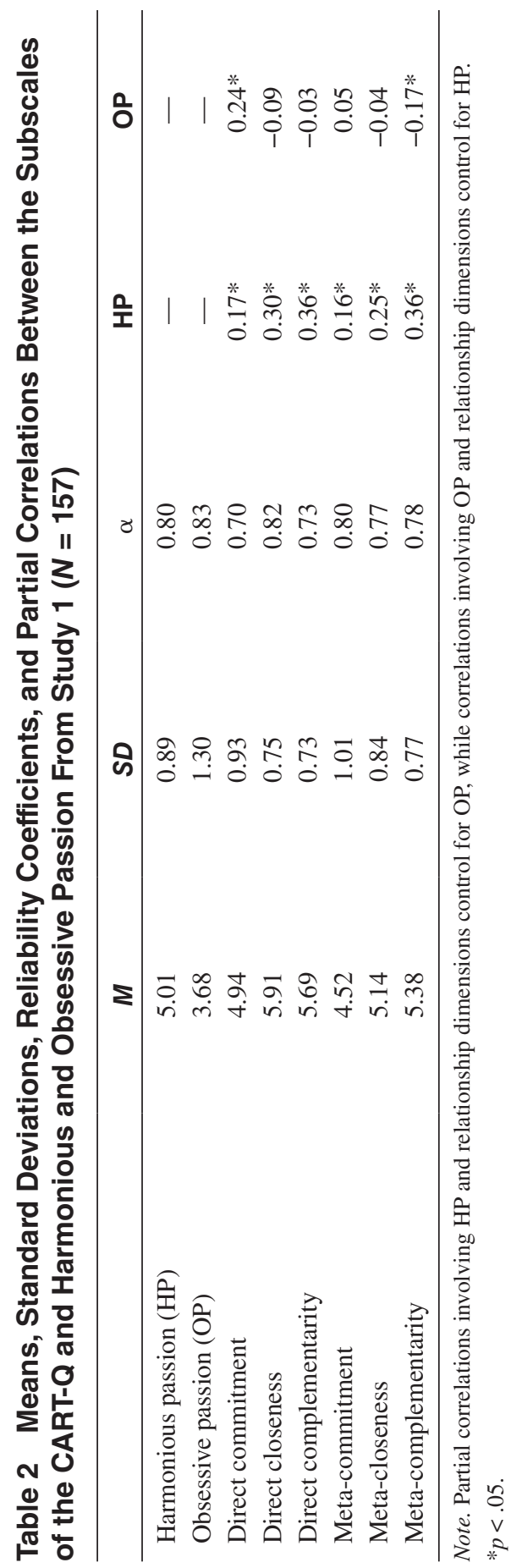


should be either unrelated or negatively related to the quality of coach-athlete relationships, because it is usually unrelated to positive emotions (Mageau et al., 2005; Ratelle et al., 2004; Vallerand et al., 2003, Study 1). Finally, we believed that a successful and fulfilling coach-athlete relationship should have positive outcomes for the coach's subjective well-being. In line with self-determination theory (Ryan \& Deci, 2007), and other need theories (see Baumeister \& Leary, 1995; McClelland, 1985), it was expected that a gratifying coach-athlete relationship should satisfy the need for relatedness (Ryan, 1995), which is expected to be conducive to higher subjective well-being. Consequently, a model was proposed in which harmonious passion should positively predict positive emotions, which in turn should be conducive to high-quality coach-athlete relationships. Subsequently, satisfying coach-athlete relationships should be contributing to higher subjective well-being. On the other hand, obsessive passion should be unrelated to positive emotions and to the quality of coach-athlete relationships.

\section{Method}

\section{Participants}

The participants were 106 French-Canadian coaches (95 males, 9 females, and 2 unspecified) engaged in one of several sports (e.g., gymnastics, basketball, football). The mean age of the participants was 35.48 years $(S D=10.83$ years). On average, coaches engaged in coaching for $14.04 \mathrm{hr}$ per week $(S D=7.96 \mathrm{hr}$ ) and had been coaching for 5.77 years $(S D=6.15$ years). The coaches were certified by the National Coaching Certification Program of Canada (NCCP) as follows: not certified $(N=2 ; 1.9 \%)$, level $1(N=12 ; 11.3 \%)$, level $2(N=55 ; 51.9 \%)$, level 3 (recommended for national competition; $N=30 ; 28.3 \%)$, and level $4(N=2$; $1.9 \%)$.

\section{Measures}

Passion for Coaching. Coaches' passion was measured using the Passion Scale (Vallerand et al., 2003). Given that the Passion Scale was used for the first time with coaches, a confirmatory factor analysis (CFA) was conducted in the current study with LISREL 8.8 (Jöreskog, \& Sörbom, 1996). In light of the relatively low number of participants, parcels were used to create six indicators by combining 2 items from the same subscale (see Kline, 2005). Results confirmed the two-factor structure of the Passion Scale, $\chi^{2}(d f=8, N=106)=14.04, p>.05 ; \mathrm{CFI}=.97$, $\mathrm{RMSEA}=.09, \mathrm{SRMR}=.06, \mathrm{GFI}=.96, \mathrm{NFI}=.94$. Internal reliability coefficients were .83 and .85 for the harmonious and obsessive passion subscales, respectively.

Situational Positive Emotions. Coaches' situational positive emotions were assessed using three items assessing positive emotions (e.g., "In general during a game, I am happy") taken from Barrett and Russell (1998). The scale was completed on a 7-point Likert scale ranging from 1 (not agree at all) to 7 (very strongly agree). The internal reliability coefficient was 87 . 
The Coach-Athlete Relationship. The Interpersonal Relationship Quality Scale (Senécal, Vallerand, \& Vallières, 1992) was employed to assess the quality of the coach-athlete relationship. The instrument consists of four items (e.g., "In general, your relationships with your players are satisfying") and was assessed on a 5-point Likert scale ranging from 1 (not at all) to 5 (extremely). The internal reliability coefficient was .85 .

Satisfaction With Life. This variable was measured using four items (e.g., "In general, my life is close to my ideal.") from the Satisfaction with Life Scale (Blais, Vallerand, Pelletier, \& Brière, 1989). The scale was completed on a 7-point Likert scale ranging from 1 (not agree at all) to 7 (very strongly agree). The internal reliability coefficient was .89 .

General Positive and Negative Affect. Coaches' affect generally experienced in life was assessed using the short PANAS scales (Watson, Clark, \& Tellegen, 1988), an instrument composed of two subscales consisted of five adjectives assessing positive affect (e.g., proud) and five adjectives assessing negative affect (e.g., nervous). There was no redundant affect between the present scale and the measure of situational positive emotions. This scale was completed on a 7-point Likert scale ranging from 1 (not agree at all) to 7 (very strongly agree). The internal reliability coefficients were .85 and .83 for positive and negative affect, respectively.

\section{Procedure}

Participation was voluntary. Participants completed the questionnaire through a variety of means. Coaches were met before a competition or a coach clinic. Each questionnaire contained a consent form and all participants were explained the general purpose of the study directly by the test administrator. Some of the questionnaires were completed in the presence of the test administrator, and others were completed at home in the absence of the test administrator and then sent by mail in a prestamped envelope.

\section{Results and Discussion}

Missing values were replaced with the mean of the valid answers to other scale items for the same individual. Inspection of the skewness and kurtosis indices for all variables in the model proved to be normal (values ranged from -.326 to .423 for skewness and from -1.062 to -.166 for kurtosis). Means, standard deviations, and Pearson correlations are presented in Table 3. The hypothesized model was tested using path analysis (i.e., a structural model with observed variables) with LISREL 8.8 (Jöreskog, \& Sörbom, 1996). They were no univariate or multivariate outliers in the current study. All bivariate scatter plots were linear and homoscedastic. Therefore, the assumption of multivariate normality was met (see Kline, 2005). The covariance matrix served as database for the path analysis and the method of estimation was maximum likelihood. The model was composed of two exogenous variables (i.e., harmonious and obsessive passion toward coaching) and three endogenous variables (i.e., situational positive emotions, interpersonal 


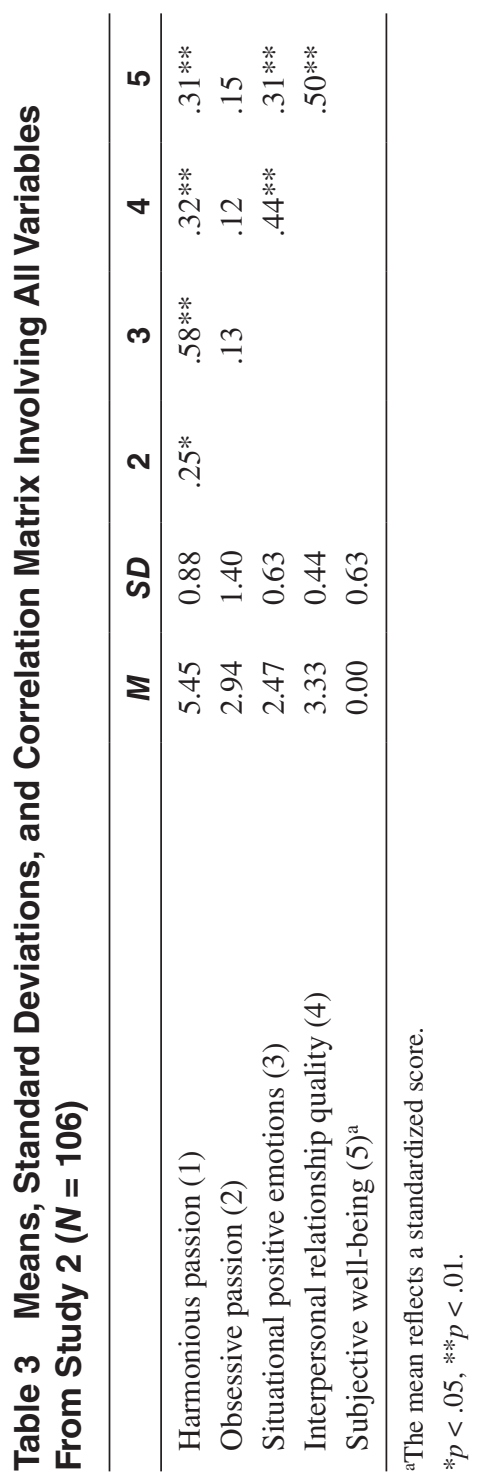




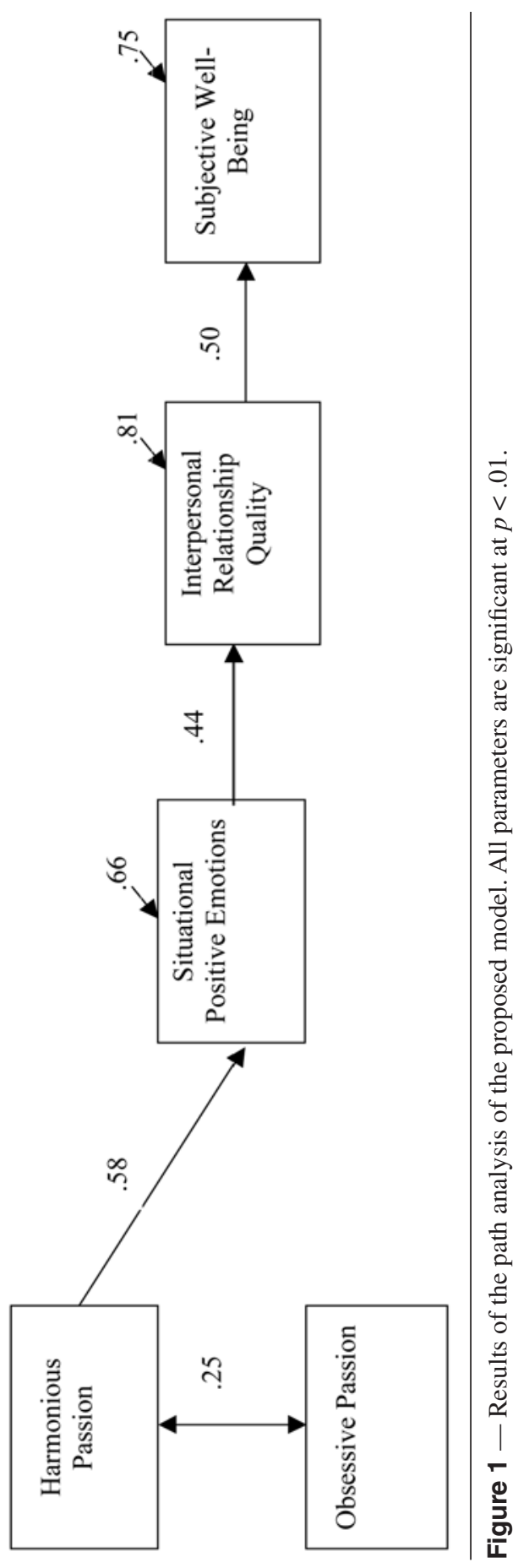


relationship quality, and subjective well-being). Moreover, in line with Diener's (2000) definition of subjective well-being, an index was created by combining coaches' life satisfaction with their general affect from the PANAS scales (e.g., see Vallerand et al., 2006). Consequently, scores for negative affect were reversed, and then all three variables were standardized and added together. This index $($ alpha $=.75)$ was used in the proposed model. Paths were specified according to the hypotheses of the theoretical model. ${ }^{2}$ Results of the path analysis revealed a satisfactory fit of the model to the data. The chi-square was not significant, $\chi^{2}(d f$ $=6, N=106)=4.82, p>.05$, and the other fit indices were acceptable, $\mathrm{CFI}=1.00$, RMSEA $=.00$, SRMR $=.07$, GFI $=.98$, NFI $=.96$, therefore indicating good model fit.

As shown in Figure 1, the estimated path between harmonious passion and situational positive emotions $(\gamma=.58)$ was significant. Moreover, the estimated path between situational positive emotions and interpersonal relationship quality was significant $(\beta=.44)$. Finally, the estimated path between the quality of coachathlete relationships and subjective well-being was also significant $(\beta=.50)$. A Sobel test was conducted to confirm the significance of the mediation of positive emotions between harmonious passion and quality of coach-athlete relationships. Results revealed a significant Sobel test $(\mathrm{z}=4.10, p<.01)$, thus confirming that the mediation effect of positive emotions was significant. Moreover, a regression analysis with standardized harmonious passion $(\beta=.082, p>.05)$ and positive emotions $(\beta=.399, p<.05)$ variables and their interaction term $(\beta=.080, p>.05)$ as predictors of the quality of the coach-athlete relationship was conducted. The relationship between harmonious passion and the quality of coach-athlete relationships was no longer significant. Therefore, the mediation was full. Then, a second Sobel test was conducted to confirm the significance of the mediation of quality of coach-athlete relationships between positive emotions and subjective well-being. Results revealed a significant Sobel test $(z=3.78, p<.01)$. Thus, the mediation effect of quality of coach-athlete relationships was significant. Furthermore, a regression analysis with standardized positive emotions $(\beta=.195, p<$ $.05)$ and quality of coach-athlete relationships $(\beta=.356, p<.05)$ variables and their interaction term $(\beta=-.076, p>.05)$ as predictors of subjective well-being was conducted. However, the relationship between positive emotions and subjective well-being was still significant. Therefore, the mediation was partial.

To ensure that the hypothesized model provided the best fit indices, seven meaningful alternative models were tested. These models were chosen because they were theoretically or statistically more plausible than other possible models. Results showed that most of these models had unacceptable fits and none had better fit indices than the proposed model. ${ }^{3}$ Thus, overall, the present findings provided support for our hypothesized model.

\section{General Discussion}

The purpose of the present research was to investigate the role of passion in the coach-athlete relationship in two studies. It was hypothesized that harmonious passion would be positively associated to the quality of the coach-athlete relationship and that obsessive passion would be either unrelated or negatively related to 
the quality of relationships. It was also posited that this effect would be mediated by the experience of situational positive emotions. These hypotheses were supported. First, results from Study 1, conducted with athletes, revealed that harmonious passion was associated with high-quality coach-athlete relationships. Conversely, obsessive passion was generally unrelated to the quality of the coach-athlete relationship, although it was positively related to commitment and negatively related to meta-complementarity. Secondly, results of Study 2, conducted with coaches, replicated Study 1's findings. In addition, results from the path analysis confirmed the mediating role of positive emotions between harmonious passion and the quality of coach-athlete relationships as well as that of the quality of coach-athlete relationships between positive emotions and coaches' subjective well-being. These findings lead to a number of implications.

\section{Passion and Interpersonal Relationships}

A first implication is that passion matters with respect to the coach-athlete relationship. Results of two studies showed that harmonious passion was positively associated with high-quality coach-athlete relationships, whereas obsessive passion was largely unrelated to such relationships. In addition, this conclusion was supported from both the coaches' and athletes' perspectives within two cultures (British and French Canadian). Of major interest are the results of Study 1 that showed that although obsessively passionate athletes are committed to the relationship with their coach, at the same time they view their coach as being uncooperative. It seems paradoxical that these athletes would be committed to a nonoptimal relationship with their coach. However, these findings are in line with the dualistic model of passion, which posits that obsessive passion leads to rigid persistence to situations (and in this case to relationships) that may be less than adaptive (see Vallerand et al., 2003, Studies 3 and 4). Specifically, rigid commitment resulting from obsessive passion can lead to persistence in a relationship even though some important negative consequences can be derived from such a relationship (e.g., frustration or even low levels of subjective well-being as shown in Study 2). Therefore, the results from Study 1 demonstrated that harmonious passion positively predicts high-quality coach-athlete relationship, whereas obsessive passion was predictive of a less-than-optimal coach-athlete relationship. Results from Study 2 also supported this conclusion from the coach's perspective, as harmonious passion was positively related to the quality of the coach-athlete relationship, whereas obsessive passion was unrelated to it. These conclusions are thus in line with those of previous research (Séguin-Lévesque et al., 2003; Vallerand et al., 2008b, Study 3) that found that having a harmonious passion is favorable, whereas obsessive passion was unbeneficial to relationships outside the passionate activity. However, the present findings extend these by showing that such effects generalize to relationships within the purview of the passionate activity.

\section{Positive Emotions as a Mediating Process}

Results of Study 2 revealed that harmonious passion indirectly predicts high-quality relationships within the passionate activity through the experience of situational positive emotions as posited by Fredrickson (2001; Waugh \& Fredrickson, 
2006). It would appear that harmonious passion leads individuals to engage in their passionate activity in a flexible manner because it is well integrated in the identity. Such a form of activity engagement leads to a greater openness to one's immediate environment and facilitates the experience of positive emotions during activity engagement (Mageau et al., 2005; Vallerand et al., 2003; Vallerand et al., 2006). These emotions then instigate interpersonal behaviors such as smiling, positive sharing of the activity, connection, and openness to others (Aron et al., 2000). Finally, such behaviors should create conditions that are conducive to positive interpersonal relationships. The present findings thus support the broadenand-build theory (Fredrickson, 2001) by demonstrating that the experience of positive affect is conducive to high-quality relationships. The results of Study 2 also showed that obsessive passion was associated neither with positive emotions nor to the quality of the coach-athlete relationships. Future research is needed to determine whether situational negative emotions engendered by obsessive passion (Vallerand et al., 2003, Study 1; Vallerand et al., 2006, Study 2) would undermine the coach-athlete relationship. In addition, since the model tested in Study 2 was obtained with only coaches, it should be replicated with athletes to determine if it also generalizes to this population.

It should also be noted that the present results revealed that high-quality coach-athlete relationships lead to higher subjective well-being. Moreover, only harmonious passion was conducive to optimal relationships which benefit coaches in terms of subjective well-being. Accordingly, the present findings are in line with self-determination theory (Ryan \& Deci, 2007) and Baumeister and Leary's need to belong (1995), which postulate that fulfilling relationships are contributing to higher subjective well-being. These findings are in line with past research on the role of passion in subjective well-being (Rousseau \& Vallerand, 2003, in press; Vallerand et al., 2007). However, they underscore the beneficial role that positive emotions and quality of meaningful relationships, such as those with one's athletes, play in the process.

\section{Limitations}

Some limitations of the present research need to be underscored. First, the correlational design used in both studies does not allow us to infer causal inferences. Study 2 proposed a model in which all variables were concurrently measured. Therefore, it is impossible to determine the directionality of causality with respect to the proposed model. Consequently, researchers should try to replicate the present findings using experimental designs to clearly establish the directionality of the effect. Second, both studies took place only at one point in time. It would be important to conduct longitudinal or prospective research to determine the role of passion in predicting the development of the coach-athlete relationship. Third, the sample of Study 2 contained a large disproportion of men $(N=95)$ and women $(N$ $=9$ ). This drawback did not permit us to investigate the issue of gender differences. Future research should look into this issue. Fourth, in Study 2, we only assessed one type of emotions. Future research should evaluate a broader range of emotions (see Yik, Russel, \& Feldman Barrett, 1999) to expand our understanding 
of the role of different emotions in mediating the relation between passion and the quality of relationships. Finally, in the present research, all variables were reported by the participants. Future research should replicate the present findings while using objective measures of the quality of relationships (e.g., the Coaching Behavior Assessment System; Smith, Smoll, \& Curtis, 1979) from both the coaches' and the athletes' perspectives.

In sum, the findings from the present research suggest that passion matters with respect to the coach-athlete relationship. It appears that harmonious passion predicts better coach-athlete relationships than obsessive passion. Moreover, this process is mediated by the experience of positive emotions and seems to contribute to coaches' higher levels of subjective well-being. To return to the introductory paragraphs, it would then appear that passion does indeed represent a crucial factor to consider when trying to predict the quality of coach-athlete relationships. Future research is needed to more firmly establish when each type of passion may affect the coach-athlete relationship, and identify the nature of the psychological processes mediating such effects.

\section{Notes}

1. We conducted regression analyses with standardized harmonious and obsessive passion variables and their interaction term as predictors of all subscales of the CART-Q (Jowett \& Ntoumanis, 2004). Results were identical to the partial correlations and no interaction terms were significant.

2. The model was initially tested with all possible paths between the model's variables. There were no significant direct paths between harmonious passion and the quality of coach-athlete relationships as well as between harmonious passion and subjective well-being. In addition, there were no significant paths between obsessive passion and all other endogenous variables of the model. We then retested the model without these nonsignificant paths. Consequently, the final model includes all significant paths existing between the variables of the structural model.

Alternative Model 1: C-A relationships $\rightarrow$ Passion $\rightarrow$ Positive emotions $\rightarrow$ SWB, $\chi^{2}(d f=7, N=106)=35.83, p<.05 ; \mathrm{CFI}=.84, \mathrm{RMSEA}=0.19, \mathrm{SRMR}=$ $0.16, \mathrm{GFI}=.88, \mathrm{NFI}=.66$.

Alternative Model 2: Positive emotions $\rightarrow$ Passion $\rightarrow$ C-A relationships $\rightarrow$ $\mathrm{SWB}, \chi^{2}(d f=7, N=106)=22.46, p<.05 ; \mathrm{CFI}=.86, \mathrm{RMSEA}=0.15, \mathrm{SRMR}=$ $0.13, \mathrm{GFI}=.92, \mathrm{NFI}=.82$.

Alternative Model 3: Passion $\rightarrow$ C-A relationships $\rightarrow$ Positive emotions $\rightarrow$ $\mathrm{SWB}, \chi^{2}(d f=6, N=106)=49.53, p<.05 ; \mathrm{CFI}=.84, \mathrm{RMSEA}=0.27, \mathrm{SRMR}=$ $0.17, \mathrm{GFI}=.84, \mathrm{NFI}=.54$.

Alternative Model 4: Passion $\rightarrow$ Positive emotions $\rightarrow \mathrm{SWB} \rightarrow \mathrm{C}$-A relationships, $\chi^{2}(d f=6, N=106)=16.33, p<.05 ;$ CFI $=.90$, RMSEA $=0.13$, SRMR $=$ $0.11, \mathrm{GFI}=.94, \mathrm{NFI}=.86$.

Alternative Model 5: SWB $\rightarrow$ C-A relationships $\rightarrow$ Positive emotions $\rightarrow$ Passion, $\chi^{2}(d f=7, N=106)=12.27, p>.05 ; \mathrm{CFI}=.96$, RMSEA $=0.09$, SRMR $=$ $0.11, \mathrm{GFI}=.96, \mathrm{NFI}=.91$.

Alternative Model 6: Passion $\rightarrow \mathrm{SWB} \rightarrow$ Positive emotions $\rightarrow \mathrm{C}$-A relationships, $\chi^{2}(d f=6, N=106)=51.97, p>.05 ; \mathrm{CFI}=.71$, RMSEA $=0.27, \mathrm{SRMR}=$ $0.18, \mathrm{GFI}=.83, \mathrm{NFI}=.53$. 
Alternative Model 7: C-A relationships $\rightarrow$ Positive emotions $\rightarrow$ Passion $\rightarrow$ SWB, $\chi^{2}(d f=6, N=106)=51.97, p<.05 ; \mathrm{CFI}=.79, \mathrm{RMSEA}=0.17, \mathrm{SRMR}=$ $0.13, \mathrm{GFI}=.92, \mathrm{NFI}=.76$.

\section{References}

Aron, A., Aron, E.N., \& Smollan, D. (1992). Inclusion of the other in the self scale and the structure of interpersonal closeness. Journal of Personality and Social Psychology, 63, 596-612.

Aron, A., Norman, C.C., Aron, E.N., McKenna, C., \& Heyman, R.E. (2000). Couple's shared participation in novel and arousing activities and experienced relationship quality. Journal of Personality and Social Psychology, 78, 273-284.

Barrett, L.F., \& Russell, J.A. (1998). Independence and bipolarity in the structure of current affect. Journal of Personality and Social Psychology, 74, 967-984.

Baumeister, R., \& Leary, M.R. (1995). The need to belong: Desire for interpersonal attachments as a fundamental human motivation. Psychological Bulletin, 117, 497-529.

Blais, M.R., Vallerand, R.J., Pelletier, L.G., \& Brière, N.M. (1989). L'Échelle de satisfaction de vie: Validation canadienne-française du "Satisfaction with Life Scale". Revue canadienne des sciences du comportement, 21, 210-223.

Csikszentmihalyi, M. (1990). Flow: The psychology of optimal experience. New York: Harpen Collins.

Deci, E.L., \& Ryan, R.M. (2000). The "what" and "why" of goal pursuit: Human needs and the self-determination of behavior. Psychological Inquiry, 11, 227-268.

Diener, E. (2000). Subjective well-being: The science of happiness and a proposal for a national index. The American Psychologist, 55, 34-43.

Fredrickson, B.L. (2001). The role of positive emotions in positive psychology: the Broadenand Build theory of positive emotions. The American Psychologist, 56, 218-226.

Hodgins, H.S., \& Knee, R. (2002). The integrating self and conscious experience. In E.L. Deci \& R.M. Ryan (Eds.), Handbook on self-determination research (pp. 87-100). Rochester, NY: University of Rochester Press.

Jöreskog, K.G., \& Sörbom, D. (1996). LISREL 8: User's reference guide (2nd ed.). Chicago: Scientific Software International.

Jowett, S. (2007). Interdependence analysis and the $3+1 \mathrm{Cs}$ in the coach-athlete relationship. In S. Jowett and D. Lavallee (Eds.), Social psychology in sport (pp. 15-27). Champaign, IL: Human Kinetics.

Jowett, S., \& Clark-Carter, D. (2006). Perceptions of empathic accuracy and assumed similarity in the coach-athlete relationship. The British Journal of Social Psychology, 45, 617-637.

Jowett, S., \& Cockerill, I.M. (2003). Olympic medalists' perspective of the athlete-coach relationship. Psychology of Sport and Exercise, 4, 313-331.

Jowett, S., \& Ntoumanis, N. (2004). The coach-athlete relationship questionnaire (CART-Q): Development and initial validation. Scandinavian Journal of Medicine \& Science in Sports, 14, 245-257.

Jowett, S., \& Poczwardowski, A. (2007). Understanding the coach-athlete relationship. In S. Jowett and D. Lavallee (Eds.), Social psychology in sport (pp. 3-14). Champaign, IL: Human Kinetics.

Kline, R.B. (2005). Principles and practice of structural equation modeling (2nd ed.). New York: Guilford.

Mageau, G.A., \& Vallerand, R.J. (2003). The coach-athlete relationship: A motivational model. Journal of Sports Sciences, 21, 883-904.

Mageau, G.A., \& Vallerand, R.J. (2007). The moderating effect of passion on the relation between activity engagement and positive affect. Motivation and Emotion, 31, $312-321$. 
Mageau, G. A., Vallerand, R. J., Charest, J., Salvy, S,-J., Lacaille, N., Bouffard, T., \& Koestner, R. (2007). On the development of harmonious and obsessive passion: The role of autonomy support, activity valuation, and identity processes. Paper submitted for publication.

Mageau, G.A., Vallerand, R.J., Rousseau, F.L., Ratelle, C.F., \& Provencher, P.J. (2005). Passion and Gambling: Investigating the Divergent Affective and Cognitive Consequences of Gambling. Journal of Applied Social Psychology, 35, 100-118.

McClelland, D.C. (1985). Human motivation. Glenview, IL: Scott, Foresman.

Poczwardowski, A., Barott, J.R., \& Peregoy, J.J. (2002). The athlete and coach: Their relationships and its meaning - Methodological concerns and research process. International Journal of Sport Psychology, 33, 98-115.

Ratelle, C.F., Vallerand, R.J., Mageau, G.A., Rousseau, F.L., \& Provencher, P. (2004). When passion leads to problematic outcomes: A look at gambling. Journal of Gambling Studies, 20, 105-119.

Rip, B., Fortin, S., \& Vallerand, R.J. (2006). The relationship between passion and injury in dance students. Journal of Dance Medicine \& Science, 10, 14-20.

Rousseau, F.L., \& Vallerand, R.J. (2003). Le rôle de la passion dans le bien-être subjectif des aînés [The role of passion in the subjective well-being of the elderly]. Revue Québécoise de Psychologie, 24, 197-211.

Rousseau, F.L., \& Vallerand, R.J. (in press). An examination of the relationship between passion and subjective well-being in older adults. International Journal of Aging \& Human Development.

Rousseau, F.L., Vallerand, R.J., Ratelle, C.F., Mageau, G.A., \& Provencher, P.J. (2002). Passion and gambling: Validation of the Gambling Passion Scale (GPS). Journal of Gambling Studies, 18, 45-66.

Ryan, R.M. (1995). Psychological needs and the facilitation of integrative processes. Journal of Personality, 63, 397-427.

Ryan, R.M., \& Deci, E.L. (2007). Active human nature: Self-Determination Theory and the promotion and maintenance of sport, exercise, and health. In M.S. Hagger \& N.L.D. Chatzisarantis (Eds.), Intrinsic motivation and self-determination in exercise and sport (pp. 1-19). Human Kinetics Europe Ltd.

Schlenker, B.R. (1985). In B.R. Schlenker (Ed.), Identity and self-identification. The self and social life (pp. 65-99). New York: McGraw-Hill.

Séguin-Lévesque, C., Laliberté, M.L., Pelletier, L.G., Vallerand, R.J., \& Blanchard, C. (2003). Harmonious and obsessive passions for the Internet: Their associations with couples' relationships. Journal of Applied Social Psychology, 33, 197-221.

Senécal, C.B., Vallerand, R.J., \& Vallières, E.F. (1992). Construction et validation de l'Échelle de la Qualité des Relations Interpersonnelles (EQRI). Revue européenne de psychologie appliquée, 42, 315-322.

Smith, R.E., Smoll, F.L., \& Curtis, B. (1979). Coach effectiveness training: A cognitive behavioral approach to enhancing relationship skills in youth sport coaches. Journal of Sport Psychology, 1, 59-75.

Vallerand, R.J. (2008). On the psychology of passion: In search of what makes people's lives most worth living. Canadian Psychology, 49, 1-13.

Vallerand, R.J., Blanchard, C.M., Mageau, G.A., Koestner, R., Ratelle, C., Léonard, M., et al. (2003). Les passions de l'âme: On obsessive and harmonious passion. Journal of Personality and Social Psychology, 85, 756-767.

Vallerand, R.J., \& Houlfort, N. (2003). Passion at work: Toward a new conceptualization. In S.W. Gilliland, D.D. Steiner, \& D.P. Skarlicki (Eds.), Emerging perspectives on values in organisations (Vol. 3, pp. 175-204). Greenwich, CT: Information Age Publishing.

Vallerand, R.J., Mageau, G.A., Elliot, A., Dumais, A., Demers, M-A., \& Rousseau, F.L. (2008a). Passion and performance attainment in sport. Psychology of Sport and Exercise, 9, 373-392. 
Vallerand, R.J., \& Miquelon, P. (2007). Passion for sport in athletes. In D. Lavallée \& S. Jowett (Eds.), Social Psychology in Sport (pp. 249-263). Champaign, IL: Human Kinetics.

Vallerand, R. J., Ntoumanis, N., Philippe, F., Lavigne, G., Carbonneau., N., Bonneville, A., Lagacé-Labonté, C., \& Maliha, G. (2008b). On being a sport fan: The role of passion and a look at the 2006 World Soccer Cup. Paper submitted for publication.

Vallerand, R.J., Rousseau, F.L., Grouzet, F.M.E., Dumais, A., \& Grenier, S. (2006). Passion in sport: A look at determinants and outcomes. Journal of Sport \& Exercise Psychology, 28, 454-478.

Vallerand, R.J., Salvy, S.J., Mageau, G.A., Elliot, A.J., Denis, P., Grouzet, F.M.E., et al. (2007). On the role of passion in performance. Journal of Personality, 75, 505-534.

Watson, D., Clark, L.A., \& Tellegen, A. (1988). Development and validation of brief measures of positive and negative affect: The PANAS scales. Journal of Personality and Social Psychology, 54, 1063-1070.

Waugh, C.E., \& Fredrickson, B.L. (2006). Nice to know you: Positive emotions, self-other overlap, and complex understanding in the formation of new relationships. Journal of Positive Psychology, 1, 93-106.

Yik, M.S., Russel, J.A., \& Feldman Barrett, L. (1999). Structure of self-reported current affect: Integration and beyond. Journal of Personality and Social Psychology, 77, 600-619.

Manuscript submitted: November 28, 2007

Revision accepted: May 6, 2008 
Copyright of Journal of Sport \& Exercise Psychology is the property of Human Kinetics Publishers. Inc. and its content may not be copied or emailed to multiple sites or posted to a listserv without the copyright holder's express written permission. However, users may print, download, or email articles for individual use. 